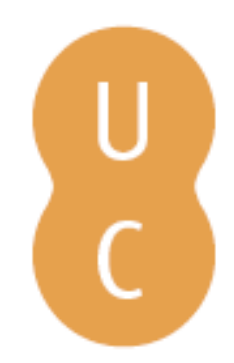

\title{
pommalina
}

\section{A coluna e o vulto: reflexões sobre o habitar na Antiguidade}

Autor(es): D'Agustino, Mário Henriques Simão

Publicado por: Imprensa da Universidade de Coimbra

URL

persistente:

URI:http://hdl.handle.net/10316.2/36669

DOI:

DOI:http://dx.doi.org/10.14195/978-989-26-1015-3_7

Accessed : $\quad$ 26-Apr-2023 04:22:52

A navegação consulta e descarregamento dos títulos inseridos nas Bibliotecas Digitais UC Digitalis, UC Pombalina e UC Impactum, pressupõem a aceitação plena e sem reservas dos Termos e Condições de Uso destas Bibliotecas Digitais, disponíveis em https://digitalis.uc.pt/pt-pt/termos.

Conforme exposto nos referidos Termos e Condições de Uso, o descarregamento de títulos de acesso restrito requer uma licença válida de autorização devendo o utilizador aceder ao(s) documento(s) a partir de um endereço de IP da instituição detentora da supramencionada licença.

Ao utilizador é apenas permitido o descarregamento para uso pessoal, pelo que o emprego do(s) título(s) descarregado(s) para outro fim, designadamente comercial, carece de autorização do respetivo autor ou editor da obra.

Na medida em que todas as obras da UC Digitalis se encontram protegidas pelo Código do Direito de Autor e Direitos Conexos e demais legislação aplicável, toda a cópia, parcial ou total, deste documento, nos casos em que é legalmente admitida, deverá conter ou fazer-se acompanhar por este aviso.

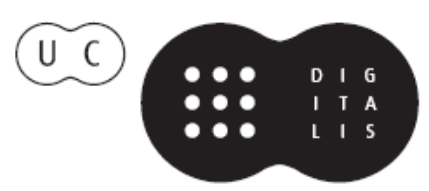


IMPRENSA DA

UNIVERSIDADE

DE COIMBRA

COIMBRA

UNIVERSITY

PRESS

\section{NA GÉNESE DAS RACIONALIDADES MODERNAS II}

Em torno de Alberti e do Humanismo

MÁRIO KRÜGER et alii

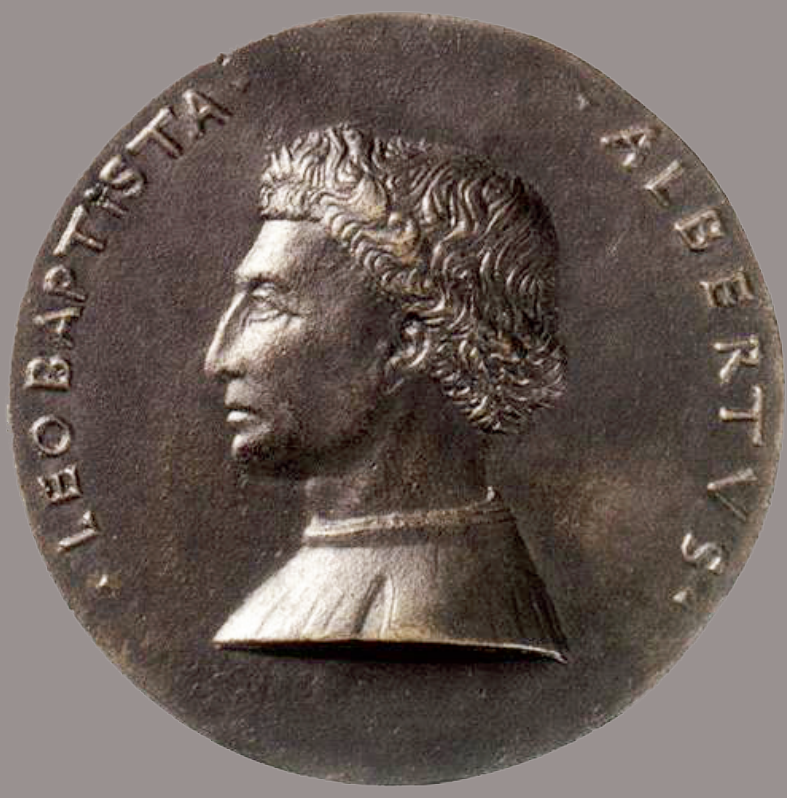




\section{A COLUNA E O VULTO.}

\section{REFLEX ÕES SOBRE O HABITAR NA ANTIGUIDADE}

Mário Henrique Simão D’Agostino

\section{Resumo}

O caráter de fixidez, permanência e firmeza da coluna, em remissão ao termo grego histēmi, é basilar para as analogias estabelecidas entre corpo e arquitetura na Grécia antiga. Considerando-o, melhor se compreende as permutas de significado com o ingresso de altas "colunas estrangeiras" nos espaços públicos da Roma tardo-republicana e protoimperial, a demarcar recorrências semânticas que perpassam a chamada tradição clássica da arquitetura.

Vitruvius; Arquitetura Clássica; Coluna; Forum Romano

\section{Résumé}

Les propriétés de fixité, de permanence et de solidité associées à la colonne, comme l'entend le terme grec bistēmi, fondent l'étude des analogies établies entre le corps et l'architecture dans la Grèce antique. Considérant cette base, on comprend mieux les transformations de sens obtenues avec l'arrivée des hautes "colonnes étrangères" dans les espaces publics de la Rome de la fin de l'époque républicaine et des débuts de l'empire. Ces nuances révèlent des récurrences sémantiques qui traversent la tradition classique de l'architecture.

Vitruvius; Architecture Classique; Colonne; Forum Romain 


\section{Summary}

The character of fixity, permanence and soundness of the column, in reference to the Greek term histēmi, is fundamental to the analogies made between body and architecture in ancient Greece. The reflection upon it improves the understanding of the exchanges in meaning brought about by the admission of high "foreign columns" in the public spaces of Late Republican and Early Imperial Rome, defining semantic recurrences that permeate the so called classical tradition in Architecture.

Vitruvius; Classical Architecture; Column; Roman foruns 
A notícia sobre o engenho dos primeiros Gregos ao comensurar as colunas de templos lígneos com symmetrias et proportiones símiles às que convêm aos corpos másculo e feminil, dóricas e jônicas, Vitrúvio a narra no Livro Quarto do De Architectura ${ }^{158}$. É sabido o interesse que tal relato desperta no curso da história e sua potência em fixar parâmetros vários para a arquitetura, não obstante a prescrição vitruviana, convergindo para a symmetría grega, distar, como atestam exegetas hodiernos, de evocações antropomórficas mais amplas. Exposta no pronau do Livro Terceiro, a analogia entre o edifício e o corpo humano advoga uma compositio na qual a referência corpórea limita-se à correspondência entre "justeza métrica" e "aptidão utilitária" das partes entre si e com o todo. Depois dos estudos clássicos de Erwin Panofsky e Rudolf Wittkower, os historiadores de arte têm se concentrado no chamado "problema da proporção"159. Todavia, boa parte do vocabulário latino e grego da arquitetura clama por aproximações antropomórficas mais imediatas, a começar por capitelum, diminutivo de caput, cabeça ${ }^{160}$. Para alguns dos mais destacados tratadistas do Renascimento (Filarete, Francesco di Giorgio, Diego de Sagredo e outros), o segundo campo morfológico não será menos descurado.

Há, no terreno das analogias antropomórficas, um aspeto que, embora não ecoe claramente nas considerações doutrinárias dos tratados, perfila-se

158 VITRÚVIO, Da Arquitetura, IV, 1, 6; citações serão tiradas da edição francesa VITRUVE, De L'Architecture, texte établi, traduit et commenté par Pierre Gros, Paris, Les Belles Letres, 1992.

159 ERWIN PANOFSKY, "História da Teoria das Proporções Humanas como reflexo da História dos Estilos”, em O Significado nas Artes Visuais, trad. de Maria Clara F. Kneese e J. Guinsburg, São Paulo, Perspetiva Ed, 1976, pp. 89-148; Rudolf WITTKOWER, "The Problem of Harmonic Proportion in Architecture", in Architectural Principle in the Age of Humanism, Great Britain, Academy Editions / St. Martin's Press, 1988, pp. 104-137; Rudolf WITTKOWER, "Sistemas de proporciones" e "Brunelleschi y la 'Proporción en la Perspetiva", en Sobre la Arquitetura en la Edad del Humanismo. Ensayos y escritos, trad. de Justo G. Beramendi, Barcelona, Editorial Gustavo Gili (col. Biblioteca de Arquitetura), 1979, pp.527-559. Dentre outros estudos contemporâneos, vide Pierre GROS, "La géometrie platonicienne de la notice vitruvienne sur 1'homme parfait (De Architectura, III, 1, 2-3), in Annali di Architettura. Rivista del Centro Internazionale di Studi di Architettura Andrea Palladio di Vicenza, n. 13, 2001; Scott DRAKE, A Well-Composed Body: Antropomorphism in Architecture, PhD Thesis, School of Enviromental Design, University of Camberra, 2003.

160 Cf. JOSEPH RYKWERT, La colonna danzante. Sull'ordine in architettura, trad. di Paola Vallerga e Paolo Iarocci, Milano, Libri Scheiwiller, 2010, p. 129; George HERSEY, The Lost Meaning of Architecture. Speculations on Ornament from Vitruvius to Venturi, Massachusetts, MIT, 1988. 
como matricial para as permutas de significado entre corpo e arquitetura na chamada Idade Clássica, qual seja: o caráter de fixidez, permanência e firmeza da coluna, em remissão ao sentido grego arcaico de hístēmi.

Na Grécia antiga, ao darem abrigo ao altar doméstico, as colunas (bistíê) recebem seu nome da lareira (bestíe), da deusa Héstia, guarnecendo-a com cobertura e permitindo a dispersão da fumaça, guardiãs do fogo sagrado que une e conserva aceso todo lar, mantendo os laços familiares tão estáveis e firmes quanto os esteios da casa. "Para os membros do oikos," observa Vernant, "a lareira, centro da casa, marca também o caminho das trocas com os deuses infernais e celestes, o eixo que, de um extremo a outro, comunica todas as partes do universo." 161

Aprendemos com Émile Benveniste, em seu Vocabulário das Instituições Indo-europeias ${ }^{162}$, que, no mundo antigo pós-homérico é sobretudo o sentido de fixidez como arraigamento, sedentarismo, permanência espácio-temporal, a estar associado à casa e seus descendentes, e tal valor de perpetuação da linhagem encontra na perenidade das colunas muito mais do que mera relação de semelhança em sentido figurado. Adito exemplos: quando Ulisses regressa a Ítaca, incitado por Penélope a identificar-se, memora à consorte a construção do leito nupcial em torno da oliveira "que medrou e frondesceu até engrossar como uma coluna" 163 . Com a imobilidade do tronco-fuste de profundas raízes exalta-se a potência imorredoura da progênie. Vitalização que se acentua em expressões como "eu diria este homem [...] coluna firme do alto teto, filho único para o pai, terra vista para marujos inesperada, sereno dia a contemplar após tormenta"164, palavras de Clitemnestra ao se dirigir ao marido regresso, ou, na Bacas de Eurípides, quando Dioniso faz

161 JEAN-PIERRE VERNANT, "Hestia-Hermes: acerca da expressão religiosa do espaço e do movimento entre os gregos", em Mito e Pensamento entre os Gregos. Estudos de psicologia histórica, trad. de Haiganuch Sarian, São Paulo, Difusão Européia do Livro / Ed. da Universidade de São Paulo, 1973, p. 154.

162 ÉMILE BENVENISTE, "I quattro cerchi dell'appartenenza sociale", in Il Vocabolario delle Istituzioni Indoeuropee, Volume Primo: Economia, parentela società, a cura di Mariantonia Liborio, Torino, Giulio Einaudi Ed. (col. Saggistica letteraria e linguistica), 1976, p. 229-ss.

163 HOMERo, Odisséia, tradução Antônio Pinto de Carvalho, São Paulo, Círculo do Livro, 1994, vv. 187-ss., p. 209.

164 ÉSQUILO, Agamêmnon, estudo e tradução de Jaa Torrano, edição bilíngue, São Paulo, Ed. Iluminuras, 2004, vv. 896-900, p. 165. 
tremer o palácio de Penteu, prenunciando a ruína maior que lhe aguarda: "[Dioniso:] Sacode o chão da terra, divino Sismo! [Coro:] $\hat{A}$ â o palácio de Penteu sacudirá até cair. Dioniso no palácio: venerai-o. - Veneramos, ó! - Vede pétreo pórtico nas colunas deslocar-se lá! [...] Prostrai no chão trêmulos corpos, prostrai, Loucas, pois o rei sobrevém derrubando o palácio, o filho de Zeus. [Dioniso:] Mulheres bárbaras tão aturdidas de pavor jazeis no chão. Parece percebestes Báquio sacudir o palácio de Penteu! Eia, levantai! Tende coragem e expulsai o tremor do corpo!"165

Os liames com a perpetuação da linhagem assumem valores tão sagrados como os da perenidade venerada nos templos. Pausânias narra a veneração em Olímpia de uma coluna tida como remanescente do palácio de Enômao, notável pelo frontispício decorado com crânios dos pretendentes à mão de sua filha, aos quais desafiava a uma corrida de cavalos em que o perdedor deveria ser morto. Firmada por círculos de ferro e um teto sustentado por quatro pilares de madeira, informa-nos o viajante, "ali está uma pequena placa de bronze que porta esta inscrição elegíaca: "Sou tudo o que resta de uma casa famosa, ó estrangeiro; fui uma coluna da casa de Enômao, e agora jazo em cadeias por obra de Zeus filho de Cronos. Agora sou venerável: o fogo temível não me devorou (...)"”166.

As permutas de significado entre corpo ereto e coluna ficam evidentes no Hino Homérico a Apolo. Atingida a colina do Parnaso nevoento, vaticina Apolo: "aqui erguer pretendo meu faustoso templo para ser o oráculo dos homens que sempre aqui virão me ofertar perfeitas hecatombes" 167 . Ele mesmo "a base instaura, ampla, contínua e compacta", sobre a qual Trofônio e Agamedes "ergueram pétreo portal"168. O caminho de Apolo conduz à Morada de Delfos, vale dizer, os destinos dos homens seguem ao oráculo pítio. Em exame à expressão verbal utilizada no Hino Homérico

165 EURíPIDES, Bacas, tradução de Jaa Torrano, edição bilíngue, São Paulo, Hucitec Ed., 1995, vv. 585-607, p. 81.

166 PAUSÂNIAS, Viagem à Grécia, V, 20, 7; Cf. JOSEPH RYKWERT, La colonna danzante, ob. cit., p. 151.

167 Hino Homérico a Apolo, vv. 287-289, in Luiz Alberto Machado CABRAL, O Hino Homérico a Apolo, introdução, tradução, comentários e notas de L. A. M. Cabral, São Paulo, Ateliê Editorial \& Editora Unicamp, p. 149.

168 Hino Homérico a Apolo, vv. 294-297, op. cit., p. 149. 
para se referir às andanças de Apolo, Detienne observa a dimensão estática nela implicada, i.e.: ter-se firmemente sobre os próprios pés, não se deixar mover ${ }^{169}$. Baínen, "caminhar", "meter o pé sobre"; acerca de seus usos e derivações, o helenista elenca: bēlós, solo; bề ma, tribuna em que o orador sobe e toma a palavra; embás ou bèlá, sapato ou sandálias; bébaios, isto que é firme, bem estabelecido ${ }^{170}$. Repõe-se assim o sentido precípuo da relação entre coluna e base; Vitrúvio nomina a segunda por stylobatum, a remeter aos vocábulos gregos stýlos, “coluna” (v., supra, alianças arcaicas entre bistîe e bestîe) e baínen, "estar em pé"171. Tais contaminações semânticas alargam as permutas entre arquitetura e corpo. Feito jogo de espelhos, se o vocábulo arquitetônico reporta-se a pé ou sandália, isto se dá seja por a coluna associar-se ao corpo ereto, seja por este, em sua performance apolínea, ser visto como coluna, a postar-se em pé duro feito pedra inamovível.

Também Walter Burkert enfatiza o zelo dos gregos com a imobilidade na ereção seja de templos como de estátuas e objetos votivos. "Como para o altar," observa, "também para o templo e imagem divina tem lugar uma cerimônia de "ereção" (hidrýein). Ofertas para a construção vêm depostas sob as paredes [...] A imagem cultual é chamada hédos, isto é, algo que possui sua "sede" imutável [...]"172. Nos textos que chegam até nós contendo referências a imagens, pinturas e esculturas, P. Martins e R. Amato igualmente observam a frequência com que os vocábulos eikón, ágalma e andriántes

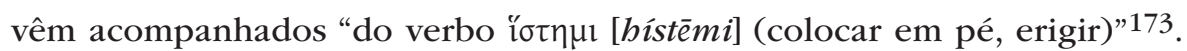

169 MARCEL DETIENNE, op. cit, p.42.

170 Ibidem, pp. 41-42.

171 Cf. JOSEPH RYKWERT, La colonna danzante, op. cit., pp. 126-27, com importantes considerações sobre a palavra grega mais usual para "base", krēpídoma, a qual igualmente significa em linguagem comum sapato ou sandália.

172 WALTER BURKERT, La Religione Greca, ob. cit., p. 202; o autor observa mais à frente: "o uso de "alçar" (anatisthénai) objetos no santuário teve claramente, desde o século VIII, um nítido e inaudito desenvolvimento, sobretudo em relação ao sacrifício votivo. O objeto "alçado", anáthema, é o dom duradouro e concreto, que testemunha a relação com a divindade"; pp. 208-09.

173 PAULO MARTINS e ROSANGELA S. S. AMATO, "Imagens antigas retoricamente referenciadas", in Adma MURANA, Mayra LAUDANNA, Luiz Armando BAGOLIN (org.) Retórica, São Paulo, Annablume Editora, 2012, pp. 133-135. 
No oikos o sucesso reservado ao varão coincide com a persistência, ruína ou restabelecimento do edifício. Relata Pausânias que, em Trezene, frente ao templo de Apolo, uma “cabana de Orestes" tinha sido construída para que o matricida em casa comum não tivesse acolhida ${ }^{174}$. À estabilidade do lar contrapõe-se, pois, a provisoriedade da choça. Outro exemplo: o falecimento de um ente familiar, e, por consequência, a interrupção do curso normal da vida doméstica, exige ritos fúnebres similares, nos quais os parentes permanecem certo tempo excluídos da vida social. Durante o recolhimento é vetado uso de roupas novas e banho, devendo-se manter a cabeça suja com cinzas ou terra. No ato final da purificação, a casa deve ser limpa, só então se reascende a lareira ${ }^{175}$.

A "purificação dos templos" evoca significados similares. Ainda Burkert: "procissões com imagens divinas - que têm grande papel no Oriente antigo - são a exceção [na religião grega]. Existe a procissão para a purificação do Paládio, por exemplo, o rapto e retorno da Hera de Samos; mas este "mover o imóvel" representa uma inquietante rutura da ordem."176 Lareira apagada, imagem cultual coberta e moção de estátuas configuram situações ameaçadoras, de instabilidade e iminente irrupção de desordem, de confronto e expurgo de forças sinistras de negação da vida. O restabelecimento do curso regular dos acontecimentos cotidianos firma-se pela renovação de normas a iterar o rigoroso regime de domicílios e domínios próprios a deuses e, por devoção sacrificial, a homens (devoção que lhes propicia lugar firme e perene, centrado pela lareira, condição de humanidade). Consumada a purificação do templo ou da casa repõe-se a fixidez ou imobilismo, a tudo convertendo em “objetos-coluna”, imóveis. Tal forma de piedade é em muitos aspetos distinta das permanências ritualísticas

174 PAUSÂNIAS, Viagem à Grécia, II, 31, 8; Cf. WALTER BURKERT, op. cit., p. 188; Cf. ÉSQUILO, Eumênides, estudo e tradução de Jaa Torrano, edição bilíngue, São Paulo, Editora Iluminuras, vv. 276-283, 2004.

175 WALTER BURKERT, op. cit., pp. 185-86 ("[...] também a casa vem purificada, aspergida com água de mar, esfregada com terra e depois limpa. Só então se tornará a sacrificar sobre a lareira doméstica, que no entretempo permanece apagada: retoma-se a normal relação com o divino"; p. 186).

176 WALTER BURKERT, La Religione Greca, ob. cit., p. 207; afinal, foi a captura do Paládio, a remoção do seu protetorado, o que tornou a cidade vulnerável e possibilitou o assédio e vitória contra os troianos. 
no universo espiritual da pólis, bem como da "economia simbólica do sagrado" no orbe filo-helenístico da Roma antiga.

Os paralelos com o rito fúnebre romano, em razão de suas similitudes, são esclarecedores. Em sua Naturalis Historia, Plínio, o Velho, lastimando a decadência da arte do retrato com o alastrar em solo itálico da estatuária greco-helenística, observa: "Bem diversos eram os retratos dos antepassados que se podiam ver nos átrios; não estátuas, obras de artistas estrangeiros, nem bronze nem mármore; eram vultos modelados em cera que vinham ordenadamente dispostos em singulares nichos feitos para receber imagens que acompanhassem os funerais gentilícios e a cada novo morto estava sempre presente a multidão de familiares vividos em tempos anteriores a ele." 177

São conhecidas as práticas arcaicas gregas de sepultamento de heróis com emprego de faixas ou máscaras de ouro com incisão de olhos a recobrir o rosto, em provável vínculo com a santificação do morto; entre romanos, porém, a alma imortal de todo vivente, homem ou mulher (genius e iuno), após a morte se converte em um deus familiar (deus parens, manes). E mais: diferentemente da fixidez das estátuas-colunas devocionais gregas, as imagines romanas são móveis, cultuadas pelo valor mesmo de tal mobilidade, a começar pelos funerais familiares, mas não só. Com o matrimônio, a filha porta consigo estátuas dos antepassados para integrá-los ao novo lar. Também as colunas se revestem de significados distintos dos gregos.

No livro sexto do De Architectura Vitrúvio traz informações mais detalhadas sobre a localização das imagines nas alas (alae) das casas ${ }^{178}$. A assimilação de esquemas tipológicos da casa grega modifica o antigo atrium tuscanicum - com complúvio central a recolher a água dos telhados, apoiados em largas vigas que alcançam as paredes laterais -, adequando-o aos modos corinthium e tetrastylon, vale dizer, átrios com espaço central guarnecido por colunas ${ }^{179}$. Convém perquirir tais vínculos

177 PLÍNIO, História Natural, XXXV, 6, in PLINIO IL VECCHIO, Storia delle Arti Antiche - Naturalis Historia Libri XXXIV-XXXVI, testo critico, traduzione e commento di Silvio Ferri, texto latino a fronte, Milano, Biblioteca Universale Risoli, 2000, p. 145.

178 VITRÚVIO, Da Arquitetura, VI, 3, 6.

179 Ibidem, VI, 3, 1. 
semânticos, claramente direcionados, em Roma, a políticas de autorrepresentação. Nos átrios e peristilos e jardins de suntuosos palácios e vilas, amplas coleções de estátuas de poetas, políticos e filósofos insignes, mormente bustos e hermas identificados por nome e epigramas inscritos no sopedâneo, exaltam os seus proprietários pelo "viver à grega". Junto a Platão, Cícero recebe os amigos em sua vila; a Aristóteles, Ático ${ }^{180}$. Na casa de Bruto, Demóstenes comparece entre os retratos dos antepassados. A Lucílio, Sêneca exorta cultuar a herança dos sábios como a dos familiares: "comportemo-nos como o bom pai de família: aumentemos o recebido. [...] devemos ter profundo respeito e venerá-los como deuses. Por que não deveria ter na minha casa também as imagens destes grandes homens, como incitamento para meu espírito? Por que não celebrar seus aniversários? Por que não nomeá-los sempre em sinal de honra? [...] Sim, eu os venero, e frente a nomes tão grandes ponho-me sempre em pé"181.

No domínio público, o ingresso das colunas e pórticos alla greca municia estupendos cenários, miríficos, perturbantes. A construção de templos ou doações de estátuas e outros ornamentos templários trazidos de campanhas militares - com ápice e ponto de inflexão quiçá na reforma do templo da Tríade Capitolina feita por Sila, após o incêndio de 83 a.C., com colunas vindas do Olympieín de Atenas-, paulatinamente cede lugar a programas de comitência edilícia exclusivamente orientados à autorrepresentação de seus fundadores - como a Porticus Metelli, edificada por Q. Cecílio Metelo Macedônico após seu triunfo em 146 a.C.; a Porticus Pompeiana, junto ao teatro e templo de Venus Genetriz, complexo inaugurado quarenta anos antes do de Marcelo, em 55 a.C.; ou o Forum Caesaris, concebido em 51 a.C. ${ }^{182}$.

180 CÍCERO, Bruto, 24; A Ático, IV, 10, 1 e 16,3.

181 SÊNECA, A Lucílio, LXIV, 7, 9-10, in SENECA, Lettere a Lucilio, traduzione e note di Giuseppe Monti, texto latino a fronte, Milano, Biblioteca Universali Rizzoli, 2001, Volume Primo (libri I-IX), pp. 391-93.

182 Cf. EUGENIO LA ROCCA, “"Graeci artifices” nella Roma reppublicana: lineamenti di storia della cultura", in GIOVANNI P. CARRATELLI (org.), I Greci in occidente, Milano, Bompiani, pp. 616-7, 621-2; Pierre GROS, L'Architettura Romana dagli Inizi del III Secolo a.C. alla Fine dell'Alto Impero. I monumenti pubblici, traduzione di Maria Paola Guidobaldi, Milano, Longanesi, 2001, p. 234, 311-12. Apropriar-se das colunas atenienses ou de estátuas alexandrinas conotava igualmente apoderar-se de seu genius, de uma potência mágica vivente nas obras. 
O significado preciso que tais "dispositivos cênicos com colunas" adquire entre as estratégias de autorrepresentação pode ser melhor compreendido por um emprego em paralelo: o de colunas encimadas por estátuas-retrato, verificável, segundo Plínio, já em 338 a.C. com a columna Maenia, a portar no fuste rostros navais, comemorativa de Caio Mênio pelas vitórias, no mesmo consulado, contra os antigos Latinos e os Anciatos. Outras, em Roma, merecem menção: no fórum, a venerabilíssima de Caio Duilio, ereta em 260 a.C., primeiro a celebrar o triunfo sobre os cartagineses; fora da porta Trigemina (entre o Aventino e o Tibre), a de Lúcio Minúcio, praefectus annonae, após coleta de uma onça por cabeça, provavelmente o primeiro a receber tal honra pelo povo, antes concedida somente pelo Senado - "coisa de grande beleza se não tivesse extraído origem de frívolos inícios", admoesta o escritor; frente à Cúria, a de Atto Navio ${ }^{183}$. Tal recurso a colunas mostra-se sempre mais ambicionado pelos notáveis. Após a vitória sobre Sexto Pompeu, filho de Pompeu Magno, na batalha de Nauloco, em 36 a.C., Otaviano recebe do Senado coluna honorífica com esporões das naus abatidas presos ao fuste, estátua triunfal no fastígio, ostentando lança e clâmide grega, significativamente localizada ao lado da columna rostrata de Duilio, junto a tribuna dos oradores no fórum ${ }^{184}$.

Para além de esteio fincado ao chão, inamovível, no orbe romano a coluna vem apreciada pelo engenho e prodígio de seu soerguimento, pela expressão de poder que encerra, tanto maior quanto mais alto se eleve - inda mais magnificente sob a força contrarrestada de quem é capaz de deslocá-la para onde quer que seja. Mais do que a fixidez, a altura e peso assumem valor precípuo. Força extraordinária de edificação, que se assimila (e se subordina) a da empresa bélica de assediar cidades, apossar-se de suas pedras, soberbas no aspeto, memoráveis, sacras. Plínio expõe claramente o significado da coluna: "A finalidade das colunas era de serem alçadas acima dos outros mortais; também este é o significado dos arcos, invenção recente"; quanto mais alta a coluna, glosa Hölscher, maior a glória do

183 Ibidem, XXXIV, 20-21, pp. 73-5.

184 PAUl ZANKER, Augusto y el poder de las imágenes, trad. de Pablo Diener Ojeda, Madrid, Alianza Editorial, 1992, pp. 63-4. 
general celebrado ${ }^{185}$. Subverte-se, pois, a analogia antropomórfica positivada no mundo grego por vínculos simpáticos; vigor e anima das pedras impõem-se como potência negativa, superação, subordinação do corpo.

A introdução das colunas marmóreas monumentais de feitio helênico nas casas da aristocracia segue pari passu as políticas edificatórias de autopromoção que marcam o derruir da República. Licínio Crasso, ferrenho defensor da retórica grega e cônsul em 95 a.C., foi o primeiro a ter "colunas estrangeiras de mármore" em sua vila no Palatino, em número de seis, com doze pés de altura, trazidas de Imetto ${ }^{186}$. Suntuosos aparatos cênicos provisórios expunham-nas à apreciação pública junto a outras estátuas nas comemorações de sua edilidade, fausto próprio de um $b a$ sileús helenístico - Bruto o apoda, em tom repreensivo, Vênus Palatina, em alusão ao filo-helenismo obsessivo, tido como cupidez e lascívia ${ }^{187}$. Menos de duas décadas depois, Marco Emílio Lépido, cônsul com Catulo em 78 a.C., será alvo de muitas censuras por até as soleiras de sua casa ele fazer com mármore lumídico, trazido em blocos; uma vez concluída, será imediatamente considerada, "no juízo unânime dos auctores", a domus mais bela de Roma ${ }^{188}$. Sua imponência agregava-se à da Basílica Emília, ambas sendo adornadas por M. Emílio com medalhões portando retratos (imagines clupeatae) de personagens militares ligados à Casa Emília189.

"No espaço de 35 anos," ajuíza Plínio, "aquela mesma casa [de Marco Emílio Lépido] tinha cem mais belas que ela; calcule, quem quiser, a massa de mármores, as obras dos pintores, as despesas reais (impendia regalis); e depois cem outras casas rivalizando com a mais bela e a mais famosa, superadas, por sua vez, por outras inumeráveis até hoje" - este

185 Ibidem, XXXIV, 27; Tonio HÖLSCHER, "Immagini e potere", in AA.VV., Storia dell'Architettura Italiana. Architettura Romana e i Grandi Monumenti di Roma, op. cit., p. 199, o autor acrescenta: "a altura da coluna indicava metaforicamente a glória do general celebrado; os rostros navais evidenciavam a dimensão desta glória na quantidade do butim. [...] esculturas sobre bases normais consentem em efeito uma vista frontal, mas depois constrangem a girar em torno a ela - enquanto a colocação sobre um arco consente continuar a avizinhar-se às esculturas atravessando-o".

186 PLÍNIO, História Natural, XXXVI, 7.

187 Ibidem, XXXVI, 7.

188 Ibidem, XXXVI, 49.

189 Ibidem, XXXV, 13. 
o testemunho magnífico de Plínio. ${ }^{190}$ Particularmente notável será a de Lúcio Lucílio Lúculo, cônsul quatro anos depois de Lépido (74 a.C.), com emprego de mármore lucúlio (dele recebe o nome) ${ }^{191}$.

Entre as obras de Lépido e as Lúculo, Emílio Escauro inicia a importação dos mármores empregados no revestimento das paredes de um teatro lígneo provisório, posteriormente destinado às comemorações de sua edilidade em 58 a.C. ${ }^{192}$ - "a maior obra jamais feita por um homem”, exclama Plínio ${ }^{193}$, a superar com suas riquezas "a loucura de Calígula e Nero, edilidade que foi por certo a principal causa da depravação dos costumes [em Roma]"194. Trezentos e sessenta colunas serão trazidas para adornar a scaenae frons do teatro, dispostas de modo a enquadrar, com aparatos cênicos em tecido "atálico" (Attalica veste), outras três mil estátuas de bronze ${ }^{195}$; ornamenta exibidos “por apenas um mês”, para deslumbre de uma plateia de oitenta mil pessoas (a cávea do teatro de Pompeu abrigará quarenta mil) ${ }^{196}$. Dessas trezentos e sessenta expostas no teatro, Escauro reservará as mais imponentes, com trinta e oito pés de altura, em mármore lucúlio, para serem transportadas ao Palatino e colocadas no átrio de sua residência ${ }^{197}$. Plínio investe: "silenciaram-se as leis sobre o fato de que tais grandes moles [de colunas] vinham transportadas para a casa privada, passando frente aos frontões em terracota dos deuses"198.

Não apenas Plínio, mas Catão, Cícero, Varrão e tantos mais professam critérios de decorum alheios aos valores enaltecidos pelas magníficas mansões e vilas tardo-republicanas e protoimperiais. Tocou a Augusto investir contra a luxúria privada. Emblemático será o confisco das colunas de mármore que M. Emílio Escauro ostentava no átrio de sua casa,

190 Ibidem, XXXVI, 109, pp. 321-323.

191 PLUTARCO, Vida de Lúculo, in Vite parallele, traduzione di C. Carena, Torino, Giulio Einaudi Ed., 1958.

192 PLÍNIO, História Natural, XXXVI, 50.

193 Ibidem, XXXVI, 114, p. 323.

${ }^{194}$ Ibidem, XXXVI, 113, p. 323.

195 Ibidem, XXXIV, 36 e 115.

196 Ibidem, XXXVI, 5 e 115.

197 PLÍNIO, História Natural, XXXVI, 6.

198 PLÍNIO, op. cit, p. 269. 
dispondo-as, como relata Ascônio, na regia do teatro de Marcelo (centro do cenário), para serem "expostas aos olhos de todos como peças preciosas e como advertência (Asc. in Scaur., 45)"199.

"O povo romano abomina o luxo privado mas ama a magnificência pública"200 - palavras de Cícero; à sua batida, Marco Agripa, riquíssimo, volve o primeiro aceno. Sua edilidade empenha-se no reparo e articulação dos aquedutos romanos, a planear um primeiro sistema integrado de abastecimento de água, compreendendo fontes, cisternas, reservatórios e outros edifícios. Como desfecho culminante dos trabalhos, Agripa "nestas construções [aquedutos e fontes] colocou trezentas estátuas de bronze ou mármore e quatrocentas colunas de mármore"201. O edil honrava, com brio, o apregoado em 33 a.C., em sua oração exorativa aos grandes homens para "tornarem de domínio público todas as estátuas e quadros que possuíssem, o que seria melhor do que mandá-las, como em exílio, às vilas" ${ }^{202}$. Colunas e estátuas subordinavam-se aos valores da magnificência pública (ornamenta urbis).

Todavia, oferecidas à visão, as colunas persistem como "bens móveis", senão veras "estátuas", colossais. Se em Roma sua altura se impõe maiormente por cancelar vínculos simpáticos com o corpo humano, como que subjugando-o a uma potência sobre-humana, isto não se consuma por um senso de mensuração que obsta a analogia corpórea (como sucederá com as columnellas góticas). Daí a persistência do animismo transfigurado em super-corpo, hipérbole que potencializa o sentido de transcendência, a se desligar da semântica grega de fixidez das colunas.

Somente nas primeiras luzes da Idade Moderna, Leon Battista Alberti, o mais ciceroniano dos arquitetos, restabelecerá, em primorosas letras latinas, os expedientes retóricos a serem observados na publica magnificentia, a prescrever claramente a ordem e hierarquia das edificações. O arquiteto observa que "os edifícios públicos [...] devem, em justa medida, ser inferiores aos sacros quanto ao decoro, igualmente as construções

199 PAUL ZANKER, Augusto y el poder de las imágenes, op. cit., p. 168; Pierre GROS, "L'auctoritas chez Vitruve", op. cit., p. 129

200 Cí́CERO, Pro Murena, 76.

201 PLÍNIO, op. cit, p. 327.

202 Ibidem, op. cit., p. 159. 
privadas devem ser superadas, adaptando-se de bom grado, pelas públicas em tudo o que respeita a elegância e riqueza dos ornamentos." 203

Memorando o dito de Tucídides ${ }^{204}$ de se construir grandes obras "para aos pósteros nós mesmos aparecermos grandes", Alberti orienta prover com máximo decoro as partes do edifício mais em contato com o público, como frontispício e vestíbulo, pontuando que o ornamento "não depende já de grandes despesas mas sobretudo da força do engenho"205. O exterior deve transmitir "solenidade" e nos ornamentos das casas da cidade "deve-se espirar um ar de severidade muito maior que nas vilas" 206 . Com dignidade austera, severitas, virtude maior da República romana, e como que respiração das imagens dos antepassados, as casas espiram um ar envolvente e solene, impondo-se, não como asfixia, mas viso manifesto a arrostar o tempo com sua presença e perpetuidade ${ }^{207}$. Não haverá outro a condensar em sua obra os significados mais profundos e persistentes da arquitetura até o limiar do século passado. Ao tratar do numerus e disposição ímpar das portas, o arquiteto observa que "também isto responde às normas da natureza, como é verificável pelo fato de nos animais as orelhas, olhos e narina serem em número par, postos lado a lado, mas no centro se encontra a boca, uma e bem ampla." 208 Cauto com a analogia vitruviana entre arquitetura e corpo, Alberti quiçá nos lega a mais fascinante das imagens antropomórficas da arte edificatória, a converter o frontispício dos edifícios privados num extraordinário gênio-máscara, persona e vulto imorredouro dos familiares.

203 LEON BATTISTA ALBERTI, L'Architettura / De Re Aedificatoria, traduzione di Giovanni Orlandi, introduzione e note di Paolo Portoghesi, Milano, Edizione Il Polifilo, 1989, IX, 1, p. 434.

204 TUCÍDIDES, História da Guerra do Peloponeso, I, 10, 2.

205 Ibidem, IX, 1, p. 433.

206 Ibidem, IX, 2, p. 436.

207 "Quantas linhagens nobilíssimas, decaídas pela injúria do tempo, teriam desaparecido de nossas cidades e de tantas outras em todo o mundo, se a lareira doméstica não tivesse mantido reunidos os sobreviventes, como que acolhidos no seio dos antepassados!"; De Re Aedificatoria, Ibidem, Prologo, p. 6; cf. PAOLO PORTOGHESI, "L. B. Alberti y su Libro "De Re Aedificatoria"”, in El Angel de la Historia. Teorías y Lenguajes de la Arquitetura, traducción de Jorge Sainz Avia, Madrid, Hermann Blume, 1985 (especif. pp. 19-23: "A exclamação contida no primeiro livro, próxima no tom a certas páginas dos livros Della Famiglia, faz pensar que a vocação de Aberti pela arquitetura nasceu precisamente da vida familiar, estrutura fundamental de toda a conceção social do humanista"; p. 20).

208 Ibidem, IX, 5, p. 454. 